\title{
THE BACTERIAL PROFILE AND ANTIMICROBIAL SUSCEPTIBILITY PATTERN OF URINARY ISOLATES IN A TERTIARY CARE HOSPITAL IN WESTERN U.P.
}

\author{
Kiran Yadav1, Gunjan Dutta², Amit Kumar Sah ${ }^{3}$
}

${ }^{1}$ Assistant Professor, Department of Microbiology, Saraswathi Institute of Medical Sciences, Hapur. ${ }^{2}$ Assistant Professor, Department of Microbiology, Saraswathi Institute of Medical Sciences, Hapur. ${ }^{3}$ Demonstrator, Saraswathi Institute of Medical Sciences, Hapur.

\section{ABSTRACT}

\section{BACKGROUND}

Urinary tract infection (UTI) is one of the common infections in the Indian community. Distribution and susceptibility of UTIcausing pathogens change according to time and place. UTI is one of the most common clinical conditions in patients presenting to the hospitals. Isolation of common pathogens and their antimicrobial susceptibility pattern is important for the adequate treatment.

The aim of this study is to determine the bacterial profile and antibiotic susceptibility pattern among pathogens isolated from patients having UTI.

\section{MATERIALS AND METHODS}

A descriptive prospective study of 325 patients suspected with urinary tract infection was processed from January 2016 to June 2016 at a tertiary care hospital according to the standard protocol.

Clean-catch mid-stream urine samples were collected in sterile container from urinary tract infected patients.

The antibiotic susceptibility of the isolated pathogens was tested by the modified Kirby-Bauer's disc diffusion antimicrobial test as per the CLSI guidelines. Standard inoculums adjusted to 0.5 McFarland was swabbed on Mueller-Hinton agar and was allowed to soak for 2 to 5 minutes. After that antibiotic disks were placed on the surface of media and pressed gently. Mueller-Hinton agar plates were then incubated at $37^{\circ} \mathrm{C}$ for $24 \mathrm{~h}$. After $24 \mathrm{~h}$, the inhibition zones were measured and interpreted by the recommendations of clinical and laboratory standards.

\section{RESULTS}

Out of 325 urine samples tested, 71 were found to be positive for microbial isolates of which 46 (25.55\%) samples were from female and 25 (17.24\%) were from males. The most common isolated organism was Escherichia coli (30.98\%). Quinolones (ciprofloxacin and levofloxacin) were sensitive for gram-negative isolates, while gram-positive isolates were sensitive to linezolid, erythromycin and quinolones.

\section{CONCLUSION}

Antibiotic selection should be based on knowledge of prevalence of the local pathogens and antibiotic susceptibility rather than on universal guidelines.

\section{KEYWORDS}

Disc Diffusion Antimicrobial Test, Drug Resistance, Urinary Tract Infection.

HOW TO CITE THIS ARTICLE: Yadav K, Dutta G, Sah AK. The bacterial profile and antimicrobial susceptibility pattern of urinary isolates in a tertiary care hospital in western U.P. J. Evolution Med. Dent. Sci. 2017;6(78):5524-5526, DOI: $10.14260 /$ jemds/2017/1200

\section{BACKGROUND}

Urinary tract infections (UTI) is one of the most important cause of morbidity in the general population, and is the second most common cause of hospital visits. UTI is also the most common cause of nosocomial infection among hospitalised patients. ${ }^{1}$ It is important to start the treatment among all the cases before getting any final microbiological report. Recurrent infections are also more common and may lead to the irreversible damage to the kidneys, resulting in renal hypertension and renal failure.

Urinary tract infections are caused by the invasion of genitourinary tract by microorganisms. Despite the advances

'Financial or Other Competing Interest': None.

Submission 10-07-2017, Peer Review 18-09-2017,

Acceptance 23-09-2017, Published 28-09-2017.

Corresponding Author:

Dr. Gunjan Dutta,

42/6, Jagriti Vihar,

Meerut-25004, Uttar Pradesh

E-mail: gundutta@gmail.com

DOI: $10.14260 /$ jemds $/ 2017 / 1200$ in the widespread availability of antimicrobials, Urinary tract infections continue to be the most common causes of infection in hospitalised patients accounting for approximately $40 \%$ of the hospital-acquired infections. ${ }^{2-3}$ UTI is mostly caused by gram-negative aerobic bacilli, which are commonly present in gastrointestinal tract. These are Escherichia coli, Klebsiella species, Enterobacter species, Citrobacter and Proteus species. Other common grampositive organisms which are also responsible are Staphylococcus aureus, Staphylococcus epidermidis, Staphylococcus saprophyticus and Enterococcus. ${ }^{4}$ Increasing multidrug resistance in bacterial uropathogens is an important and emerging public health problem because of their characteristic of very fast rise and spread of mutant strains and hence these are insusceptible to medical treatment.

The early treatment of UTI decreases the rate of morbidity, implying that in most cases antimicrobial therapy be prescribed empirically. ${ }^{5}$ The Infectious Disease Society of America (IDSA) identified some microorganisms for new effective therapies. Those microorganisms were called 
"ESKAPE pathogens," which include Enterococcus faecium, S. aureus, Klebsiella spp., Acinetobacter spp., Pseudomonas spp. and Enterobacter spp. increasing drug resistance in UTI needs regular monitoring of the antibiotic susceptibility of uropathogens in a particular area. Antibiotics are usually given before the laboratory results of urine culture are available. To ensure appropriate therapy, current knowledge of the organism that causes UTI and their antibiotic susceptibility is mandatory. ${ }^{6}$ Due to high rise in antibiotic resistance among uropathogens, it is important to have hospital-based knowledge of the organism causing UTI and their antibiotic susceptibility patterns. ${ }^{7}$ Several factors interfere like sex and age of disease, hospitalisation and obstruction in urinary tract with its natural resistance to infections. Females are however believed to be more affected than males. ${ }^{8}$ UTI has to be distinguished from other diseases that have a similar clinical presentation. The rise of antimicrobial resistance in uropathogens, probably due to the empirical choice of antibacterial therapy even before the availability of the urine culture results, is a matter of growing concern worldwide. ${ }^{9}$

So this study was done to gain the knowledge about the type of pathogens responsible for UTI and the antimicrobial susceptibility pattern of isolates in the local perspective.

\section{MATERIALS AND METHODS}

A descriptive prospective study was carried out at a tertiary hospital from January 2016 to June 2016 in Western Uttar Pradesh. Early morning clean-catch mid-stream urine samples were collected in sterile container from urinary tract infected patients. The semi-quantitative method was done on Cysteine lactose electrolyte deficient (CLED) agar with the help of calibrated sterile $4 \mathrm{~mm}$ Nichrome wire loop and then plates were incubated at $37^{\circ} \mathrm{C}$ aerobically for 24 hours and then these plates were observed macroscopically for the bacterial growth. Identification of bacterial pathogens was done on the basis of gram reactions, morphology, biochemical reactions and cultural characteristics. The culture which showed $>10^{5} \mathrm{CFU} / \mathrm{mL}$ were considered as suggestive of significant bacteriuria.

Isolates were tested for antimicrobial susceptibility by Kirby-Bauer's disc diffusion method on Mueller-Hinton Agar using the antibiotics supplied by HiMedia, India. ${ }^{10}$ Antibiotics used for Gram-Negative Bacteria were Ampicillin, Ampicillin/sulbactam, Cefuroxime, Levofloxacin, Ciprofloxacin, Norfloxacin, Linezolid, Meropenem, Nalidixic Acid, Nitrofurantoin, Tobramycin and Cefazolin. For grampositive organisms, Oxacillin, Penicillin and Vancomycin were used. The results were interpreted as per Clinical and Laboratory Standard Institute (CLSI) guidelines. ${ }^{11}$

Escherichia coli ATCC 25922, Staphylococcus aureus ATCC 25923, Pseudomonas aeruginosa ATCC 27853 was used as control strains for antibiotic sensitivity testing.

\section{RESULTS}

Out of 325 urine samples processed, 71 samples showed significant bacterial growth [Table 1]. Out of 71 positive samples 46 samples (25.55\%) were from females, thus showing female predominance. The most common bacteria isolated was Escherichia coli (30.98\%) followed by Klebsiella (26.76\%) and Pseudomonas (25.35\%) [Table 2].

The antibiotic susceptibility pattern of the isolated organisms has been shown [Table 3]. Escherichia coli showed a higher sensitivity with Ciprofloxacin (95\%), Klebsiella and Citrobacter with Meropenem (90\%) and gram-positive isolates with Linezolid (95\%).

\begin{tabular}{|c|c|c|}
\hline Sex & Total Case & Positive Cases (\%) \\
\hline Male & 145 & $25(17.24 \%)$ \\
\hline Female & 180 & $46(25.55 \%)$ \\
\hline Total & $\mathbf{3 2 5}$ & $\mathbf{7 1}(21.84 \%)$ \\
\hline \multicolumn{3}{|c|}{ Table 1. Sex-Wise Distribution of Cases } \\
according to their Test Results (n= 71)
\end{tabular}

\begin{tabular}{|c|c|}
\hline Organisms & Positive Cases (\%) \\
\hline Escherichia coli & $22(30.98)$ \\
\hline Klebsiella & $19(26.76)$ \\
\hline Pseudomonas & $18(25.35)$ \\
\hline Citrobacter & $07(09.85)$ \\
\hline $\begin{array}{c}\text { Others (S. aureus and S. saprophyticus) } \\
\text { Table 2. Organism-Wise Distribution of } \\
\text { Positive Cases (n= 71) }\end{array}$ \\
\hline
\end{tabular}

\begin{tabular}{|c|c|c|c|c|c|}
\hline Antibiotics & $\begin{array}{c}\text { Escherichia coli } \\
\text { (22) }\end{array}$ & $\begin{array}{l}\text { Klebsiella } \\
\text { (19) }\end{array}$ & $\begin{array}{c}\text { Pseudomonas } \\
\text { (18) }\end{array}$ & $\begin{array}{c}\text { Citrobacter } \\
\text { (07) }\end{array}$ & $\begin{array}{c}\text { Others } \\
(\text { Gram }+)(05)\end{array}$ \\
\hline Ampicillin & 14 & 12 & 14 & 04 & 03 \\
\hline Ampicillin sulbactam & 16 & 14 & 15 & 05 & 03 \\
\hline Cefuroxime & 16 & 14 & 13 & 05 & - \\
\hline Ciprofloxacin & 18 & 16 & 16 & 06 & 04 \\
\hline Levofloxacin & 17 & 16 & 15 & 05 & 04 \\
\hline Norfloxacin & 16 & 15 & 13 & 05 & 03 \\
\hline Linezolid & 12 & 11 & 10 & 03 & 04 \\
\hline Meropenem & 16 & 17 & 16 & 06 & - \\
\hline Nalidixic Acid & 07 & 06 & 09 & 03 & 03 \\
\hline Nitrofurantoin & 15 & 08 & 08 & 02 & 01 \\
\hline Tobramycin & 10 & 09 & 10 & 04 & 02 \\
\hline Cefazolin & 16 & 14 & 15 & 04 & - \\
\hline Erythromycin & - & - & - & - & 04 \\
\hline Oxacillin & - & - & - & - & 04 \\
\hline Penicillin & - & - & - & - & - \\
\hline Vancomycin & - & - & - & - & - \\
\hline
\end{tabular}




\section{DISCUSSION}

This study was done to evaluate the susceptibility pattern of bacterial strains isolated from UTI patients.

Diagnosis of UTI is a good example of the importance for close cooperation between the clinician and the microbiologist. Therefore, for the successful eradication of Urinary Tract Infection by using the empiric treatment, knowledge of local aetiologic agents and their antibiotic susceptibility is of great value. Even by using preventive measures and advance therapy, UTI still is the most common problem in both hospitalised and outpatients. This may be due to the increase in age, prolonged hospitalisation and inadequate personal and environmental hygiene. ${ }^{12}$ The overall prevalence of uropathogens in this study was found to be $21.84 \%$. The most predominant bacteria isolated in this study were Escherichia coli, which is similar to other studies was done in UTI patients. ${ }^{13}$ Virulence factors like haemolysin production and presence of fimbriae in Escherichia coli may be associated with urovirulence. Comparatively females will develop UTI more commonly than males, probably due to their short urethra, its proximity to anus, dilatation of urethra and the stasis of urine during pregnancy.2,9 In our study also, the prevalence of UTI in females $(74.19 \%)$ is more as compared to males (65.78\%).14 The most susceptible antibiotics in our study were Ciprofloxacin, Levofloxacin, Erythromycin and Linezolid (in gram positive), because they inhibit most commonly isolated UTI pathogens. This is similar to other studies where fluoroquinolones were the most effective. ${ }^{15}$ Nitrofurantoin, Ampicillin and Nalidixic acid were poorly effective against majority of the isolated organisms. The resistance in antibiotics among uropathogens will interfere with an effective treatment. In the developing countries, the emergence of antibiotic resistance in the control of UTI is a serious public health issue due to high level of poverty ignorance and poor hygiene. ${ }^{7}$

\section{CONCLUSION}

The present study shows that most of the isolated organisms were sensitive to Ciprofloxacin, Levofloxacin and Erythromycin. Resistance rates to Nitrofurantoin, Nalidixic acid and Ampicillin were high. The escalation of drug resistance among the uropathogens poses a global threat. To combat this drug resistance in uropathogens, choice of empirical antibiotic therapy should be based on the local prevalence of bacterial organism, predisposing factors and their antibiotic susceptibility rather than on universal guidelines.

\section{REFERENCES}

[1] Ronald AR, Pattullo AL. The natural history of urinary infection in adults. Med Clin North Am 1991;75(2):299-312.

[2] Kamat US, Fereirra A, Amonkar D, et al. Epidemiology of the hospital acquired urinary tract infections in a medical college hospital in Goa. Indian J Urol 2009;25(1):76-80.
[3] Babypadmini S, Appalaraju B. Extended spectrum lactamases in urinary isolates of Escherichia coli and Klebsiella pneumoniae-prevalence and susceptibility patterns in a tertiary care hospital. Indian J Med Microbiol 2004;22(3):172-4.

[4] Chedi BAZ, Wannang NN, Halliru MA, et al. A seven months retrospective study on urinary tract infection among patient at Aminu Kanu teaching hosp. KanoNigeria. Bayero J Pure Appl Sci 2009;2:95.

[5] Francesco MA, Ravizzola G, Peroni L, et al. Urinary tract infections in Brescia, Italy: etiology of uropathogens and antimicrobial resistance of common uropathogens. Med Sci Monit 2007;13(6):BR136-44.

[6] Tankhiwale SS, Jalgaonkar SV, Ahamad S, et al. Evaluation of extended spectrum beta lactamase in urinary isolates. Indian J Med Res 2004;120(6):553-6.

[7] Wasnik DD, Tumane PM. Prevalence and antimicrobial susceptibility pattern of urinary tract infection causing human pathogenic bacteria. Asian Journal of Biomedical and Pharmaceutical Sciences 2012;2(15):1-3.

[8] Acharya VN. Urinary tract infection-a dangerous and unrecognized forerunner of systemic sepsis. J Postgrad Med 1992;38(2):52-4.

[9] Oladeinde $\mathrm{BH}$, Omoregie R, Olley $\mathrm{M}$, et al. Urinary tract infections in a rural community of Nigeria. $\mathrm{N}$ Am J Med Sci 2011;3(2):75-7.

[10] Bauer AW, Kirby WM, Sherris JC, et al. Antibiotics susceptibility testing by a standardized single disc method. Am J Clin Pathol 1966;45(4):493-6.

[11] Clinical and Laboratory Standard Institute. Performance standards for antimicrobial disc susceptibility tests. NCCLS documents M $100 \mathrm{~S} 15$. Wayne, PA, USA: Clinical and Laboratory Standard Institute. 2005.

[12] Davoodian P, Nematee M, Sheikhvatan M. Inappropriate use of urinary catheters and its common complications in different hospital wards. Saudi Journal of Kidney Diseases and Transplantation 2012;23(1):63-7.

[13] Manikandan S, Ganesapandian S, Manoj S, et al. Antimicrobial susceptibility pattern of urinary tract infection causing human pathogenic bacteria. Asian Journal of Medical Sciences 2011;3(2):56-60.

[14] Hasan AS, Nair D, Kaur J, et al. Resistance pattern of urinary isolates in a tertiary Indian hospital. J Ayub Med Coll Abbottabad 2007;19(1):39-41.

[15] Kandaki Olukemi YT, Kolawole OM, Durowade KA, et al. Prevalence of urinary tract infections (UTI) among patients attending Dalhatu Araf Specialist hospital, Lafia, Nasarawa State, Nigeria. International Journal of Medicine and Medical Sciences 2009;1(5):163-7. 